\title{
PABLO DE OLAVIDE Y JÁUREGUI, UN CATÓLICO ILUSTRADO
}

\author{
José Luis Gómez Urdáñez \\ Diego Téllez Alarcia* \\ Universidad de La Rioja
}

Carlos III fue antes de nada un rey absoluto. Incapaz de imaginar que el poder de un monarca de la Católica España pudiera ser limitado, retuvo el control de la Inquisición, conservando la prerrogativa de nombrar a los inquisidores, e impidiendo cualquier atisbo de reforma del Tribunal, una vía que consideró definitivamente cerrada ya en 1762-63, cuando dio carpetazo al proyecto de reforma de los consejeros de la Suprema, Cantos y Ric. Las "Prevenciones y Precauciones" que estos dos consejeros, recomendados por el propio Ricardo Wall, ministro de Estado, pusieron en manos del monarca comenzaban ratificando "que le correspondía designar (al Rey) a todos los empleados de la Inquisición", pero ni así lograron su plácet; tampoco el de su confesor, el padre Eleta'.

Este fraile gilito fue, en efecto, el contrapunto recalcitrante a la tan aireada como escasa ilustración del monarca. Generalmente relegado en la historiografía filocarolina, su intervención en la toma de decisiones del monarca fue espectacular y desde luego tan visible o más que la de sus predecesores Rávago o Quintano Bonifaz. Muchos de los calificativos que se le han propinado a Eleta parecen insultos -Azara le Ilamó "el Alpargata, el Gran Mufti, el Júpiter del Cordón o fray Pernetas" ${ }^{2}$, pero muchos no lo son. Su mentalidad era supersticio-

* Este artículo se encuadra en el proyecto de investigación "Reconstrucción prosopográfica de clientelas políticas en la España de mediados del XVIII (1743-1763)" (BHA2003-07360), patrocinado por el MCyT.

1. Ver Ricardo Gómez-Rivero, El Ministerio de Justicia en España (1714-1812) (Madrid: Centro de Estudios Políticos y Constitucionales, 1999), 673-674. Antonio Álvarez de Morales, Inquisición o Ilustración (1700-1834) (Madrid: Fundación Universitaria Española, 1982), 93-102.

2. José F. Alcaráz Gómez, Jesuitas y reformismo. El padre Francisco de Rávago (1747-1755) (Valencia: Facultad de Teología San Vicente Ferrer, 1995), 75. 
sa, como argumentó Ferrer del Río. Sobre su influencia en el rey, Casanova escribió: Carlos III "era testarudo como una mula, débil como una mujer, sensual como un holandés, muy devoto y decidido a morir antes que macular su alma con el menor pecado mortal. A cualquiera le será fácil darse cuenta de que semejante hombre debía de ser esclavo de su confesor" ${ }^{\prime \prime}$.

Con todo, el confesor se oscurece en la historiografía carolina, seguramente a causa de la poderosa personalidad de los políticos de Carlos III y de la dirección de las reformas -dos lugares comunes en la hagiografía progresista-, que en materia de relación con la Iglesia Ilegaron al cénit con el sonado éxito de famille de la expulsión y posterior extinción de los jesuitas (1767-73). Había triunfado el Absolutismo Regio a través de su brazo militar, que no era otro que el conde de Aranda, mientras el control social -el principal servicio del viejo Santo Oficio- estaba ya asegurado en pleno siglo de las luces. Parece una contradicción, pero fue, precisamente, el propio Aranda el que más contribuyó a robustecer la idea de rey absoluto que Ilegó a asumir Carlos III (muy diferente a su hermanastro Fernando VI, a quien Ensenada y Carvajal convencieron de su papel de "reformador"), un resbalón más del jefe del "partido" aragonés, presuntamente más "pactista", que de esa forma vino a confundir el absolutismo del rey, de viejo cuño, con el moderno despotismo ilustrado, el motor real de las reformas ${ }^{4}$.

En adelante, la política reformista se presentó con habilidad: no sólo como obra de "la Trinca" -Aranda, Campomanes y Olavide- ${ }^{5}$, sino del propio rey -que así se hacía ilustrado, como decían que eran los reyes europeos-. Sin embargo, la reacción "política" -ya veremos la del marqués de la Corona, muy sintomática - y la atmósfera de escándalo producido por las novedades en el mundo de las ideas, la moral y las costumbres (eso es la Ilustración en España) no iban a ceder en todo el reinado, encontrando en el propio entorno del rey los más activos interlocutores y oponentes, sobre todo el padre Eleta, la figura clave en el escenario. Sólo hacían falta hechos desencadenantes, y uno fue el

3. Giacomo Casanova, Memorias (Madrid: Aguilar, 1982), vol. V, 162.

4. Como demostró R. Olaechea, Aranda tenía "un concepto teocrático de la monarquía". En carta al futuro Carlos IV, Aranda llega a justificar el origen divino (lo que en España fue considerado algo estrafalario por lo general): "Puesto que Su Majestad está en ejercicio del vicariato del mundo, que el Dios supremo depositó en ella, como un representante...", Rafael Olaechea y J. I. Gómez Zorraquino, "El partido aragonés y la política ilustrada en España", Los tiempos dorados, Estudios sobre Ramón Pignatelli y la Ilustración" (Zaragoza: Instituto Fernando el Católico, 1996), 195.

5. Incluyendo a Grimaldi, formaban la cúpula de los reformistas. Así lo describía Paolo Frisi a Beccaria: "gli sforzi di tre nuovi Bacchi, ovvero Orfei, i quali hanno cominciata la rivoluzione. Il marquese Grimaldi, coll'aperta protezione delle scienze e delle arti, il conte d'Aranda, col perfezionare la pubblica economia e polizia e il fiscale Campomanes col distruggere gli inveterati pregiudizi della jurisprudenza ecclesiastica". Frisi a Beccaria, 17 de octubre de 1775, Cesare Beccaria, Dei delitti e delle pene (Torino: Einaudi, 1965), 569. 
desastre de Argel de 1775 que produjo un clima de tensión similar al que se vivió en $1766^{6}$. Inmediatamente después, alguien debía pagar...

En ese contexto, el arandista Pablo de Olavide y Jaúregui (Lima, 1725-Baeza, 1803) era denunciado a la Inquisición.

\section{Olavide, el ilustrado afrancesado}

Como la riqueza era uno de los fundamentos de la libertad y de la necesaria despreocupación, antesala del cultivo de las luces -Voltaire dixit-, el rico y joven Olavide (nacido en Lima en 1725) viajó por Italia y Francia, conoció a los filósofos, visitó al señor des Delices, compró libros y ...filosofó despreocupadamente. A su llegada a Madrid, en 1765, adonde se había hecho enviar miles de libros en francés -previa obtención de licencia para leer libros prohibidos: todo lo podía el dinero-, le fue fácil hacerse un hueco en los salones de la aristocracia ${ }^{7}$, en donde encontró a algunos de los grandes personajes Ilamados a servir al rey Carlos III, cuya brillante obra había podido admirar personalmente el peruano al pasar por Nápoles. A sus cuarenta años, la carrera pública de este "afrancesado" - uno más-, deslumbrado por la France des philosophes y l'Encyclopédie, sólo esperaba la mano poderosa que le llevara a un cargo público, que iba a ser -cómo nola del conde de Aranda, un militar también viajado en su juventud, educado por los jesuitas, igualmente "afrancesado" -y prusiano en su pasión por la carrera de las armas-, feo, rudo, soberbio y mandón, pero... ilustrado.

El presidente Aranda probó a Olavide en varios cargos -director del hospicio de San Fernando, síndico del ayuntamiento madrileño- antes de confiarle la dirección de la obra ilustrada del siglo, las Nuevas Poblaciones de Sierra Morena, un mundo nuevo creado bajo normas racionales, una Nueva Arcadia en la que se podría experimentar con un concepto entonces muy sospechoso: le bonheur, la felicidad terrenal. Como observó el siempre recordado Ernest Lluch, ya en la segunda línea de la Instrucción de 1767 de Olavide aparecía la palabra "felicidad $^{\prime \prime}$, un término peligroso si no se refería a la felicidad verdadera, que no podía ser sino el premio en el cielo a las fatigas y penalidades pasadas en la tierra.

La idea de la colonización en la España despoblada -poco más de ocho millones de habitantes (más de veinte en Francia)- era vieja: a más población, más riqueza, o como diría el marqués de la Ensenada: a más súbditos, más contribuyentes y más riqueza para el estado. El poblacionismo, verdadera obsesión

6. Teófanes Egido, Los Borbones. Carlos IV. (Madrid: Arlanza, 2001), 41.

7. Según Sarrailh, "después de su matrimonio con la riquísima viuda Isabel de los Ríos, su casa se había convertido en centro de reunión de todos cuantos seguían la moda", Sarrailh, La España Ilustrada, 620. Sobre Olavide son de obligada referencia Marcelin Defourneaux, Pablo de Olavide o el afrancesado, (Sevilla, 1990); y Perdices de Blas, L., Pablo de Olavide (17251803), El Ilustrado, (Madrid: Complutense, 1995).

8. Véase Ernest Lluch, Las Españas vencidas del siglo XVIII, Claroscuros de la Ilustración (Barcelona: Crítica, 1999), 153. 
dieciochesca en España, fue preconizado por los proyectistas de Felipe V, incluso por un ministro a la antigua como José de Carvajal, quien pensó en buscar colonos en Santiago de Compostela entre los peregrinos (así se aseguraba su fe católica) ${ }^{9}$. La matizaron hombres como Ward en su Proyecto Económico ${ }^{10}$, que conocía bien algunos reparos, "El primero son tales las impresiones que tienen las gentes en todas partes de la Inquisición, que aún los católicos más celosos la tienen cobrado un miedo y un odio notable"11.

Los argumentos a favor de la colonización fueron reelaborados en el plano económico por Campomanes, quien había leído todo sobre el asunto, incluidas las propuestas prácticas del francés Beaumarchais y la del aventurero bávaro Thurriegel. Mientras, Aranda aportaba la experiencia alemana, el conocimiento que tenía de los asentamientos que, manu militari, estaba estableciendo su admirado Federico II $^{12}$. La misión ilustrada del siglo brotaba de las mejores fuentes -españolas y extranjeras- y era "bendecida" por el propio Carlos III, a cuyo nombre se tributaba el establecimiento principal, La Carolina, el pueblo donde el flamante superintendente Olavide edificó su palacio, un robusto y confortable edificio coronado con el escudo real. A su lado, descentrada con respecto a la calle principal del pueblo, estaba la humilde iglesia parroquial...

\section{Olavide, libertino}

Con Olavide ya al frente de la gran empresa ilustrada, empezaron a llegar los colonos y también, obviamente, los problemas. Casanova, que conoció el clima de críticas que empezaba a nacer contra Olavide, bromeó con el origen de los pobladores, "Suiza -escribió-, el pueblo más sujeto a la nostalgia", y hasta pudo dar alguna recomendación al superintendente, "en lo tocante a sus conciencias (a las de los suizos católicos)". Conocedor de que "Olavide afirmaba rotundamente que había que evitar todo tipo de establecimiento de frailes", el italiano le aconsejó -eso escribe en sus memorias- que "haría falta por lo menos en los primeros tiempos, darles sacerdotes y magistrados suizos", lo que a regañadientes Olavide tendría que hacer, pues los colonos no hablaban castellano y no podían entender a los párrocos españoles. Al poco, el superintendente resolvió el engorroso trámi-

9. José Miguel Delgado Barrado, José de Carvajal y Lancáster. Testamento político o idea de un gobierno católico (1745) (Córdoba: Universidad de Córdoba, 1999).

10. Proposición de Mr. Bernardo Ward para establecer colonias agrícolas e industriales de irlandeses en España. Ward a Ordeñana, Londres, 21 de octubre de 1753, en Antonio Rodríguez Villa, Don Zenón de Somodevilla, marqués de la Ensenada. Ensayo biográfico (Madrid: Librería de M. Murillo, 1878), 361.

11. Que no existieron en el caso de la "importación" de ingenieros navales ingleses llevado a cabo por Jorge Juan, bajo los auspicios del "jesuitón" Ensenada. Véase José Luis Gómez Urdáñez, El proyecto reformista de Ensenada (Lleida: Milenio, 1996).

12. Véase J. M. Sánchez Diana, "El despotismo ilustrado de Federico el Grande y su influencia en España", Arbor XXVII, (1948): 100. 
te -vendrían unos frailes alemanes-, y pasó a ocuparse de otros asuntos, entre ellos los de tipo económico, siempre problemáticos ${ }^{13}$.

Al comenzar la década del Setenta, las críticas sobre la colonización empezaban a generalizarse: se comentaba especialmente el gasto excesivo que acarreaban las Nuevas Poblaciones, la mala administración del superintendente y sus amigos, incluso el despilfarro, pero sobre todo, algunas notas personales contra el disoluto Olavide, que necesariamente tenían que aparecer: tal era su fama de hombre libre y sin prejuicios. El fiscal Carrasco, marqués de la Corona, escribió un durísimo alegato que puede ser tomado como la punta de lanza de las fuerzas conservadoras contra el peruano. En resumen, para este resentido personaje, la causa del fracaso estaba en "confiar la ejecución a una mano tan desacreditada como la de Olavide". La Corona, que también terciaba en su escrito sobre la reforma de la Inquisición, terminaba sentenciando: "Pobre rey y pobre España con ministros tan flacos y tan insensibles a su servicio"14. La inquina sobre un personaje que sólo se debía a los apoyos de sus importantes amigos - no era noble, ni siquiera español- empezaba a concitar la animadversión de los que buscaban abrir una brecha en el edificio que intentaban construir los ilustrados al lado del rey.

Aumentaron las críticas contra un plebeyo medrado y, además, iba resquebrajándose la "unidad del equipo ilustrado", es decir, las buenas relaciones entre sus amigos: Campomanes, Aranda y Grimaldi. ${ }^{15}$ Era evidente que se estaba produciendo un cambio, pero no lo entendió Olavide, que continuaba exhibiendo sus ideas ante cualquiera, sin saber que todo lo que hacía era amplificado y dirigido hacia arriba, y que cada vez tenía menos protección. Siguió siendo, como le declaró Menéndez Pelayo un "iluso de filantropía"16.

Paradójicamente, cuando Olavide conoció al que iba a ser su feroz enemigo, fray Romualdo de Friburgo, se alegró. Al fin se quitaba un problema de encima, pensó. El barbado fraile capuchino, un alemanote serio con abundantes dotes de mando, Ilegaba tras los primeros "hermanos" enviados desde Friburgo para meterles en cintura. Eso es lo que pensó cándidamente Olavide, pues los frailes habían empezado a crear problemas.

Fray Romualdo Ilegó a la Carolina el 13 de mayo de 1770. Olavide tuvo con él un primer "desencuentro", pues el orgulloso capuchino no admitió en modo

13. Casanova, Memorias, vol. V, 163-164. Sobre el balance económico, véase Perdices Blas, Pablo de Olavide, 1995 y Manuel Capel Margarito, La Carolina, capital de las Nuevas Poblaciones (Jaén: Instituto de Estudios Jienenses, 1970).

14. El original de los Cuadernos sobre gobierno y administración, en Archivo Histórico Nacional (en adelante AHN), Estado, leg. 3211-2.

15. Ver Janine Fayard y Rafael Olaechea, "Notas sobre el enfrentamiento entre Aranda y Campomanes", Pedralbes. Revista D'Historia Moderna 3 (1983): 5-59.

16. Marcelino Menéndez Pelayo, Historia de los heterodoxos españoles (Madrid: C.S.I.C., 195). El erudito vio en él "cierta cándida y buena fe", lo que le hacía "a ratos simpático". 
alguno que el superintendente no le aceptara la jefatura total de su misión, que se atribuía mediante la simple exhibición de una "patente" de su orden. Ante la sorpresa de Olavide, que ya había transigido mucho permitiendo frailes en las Poblaciones, Romualdo perseveró; al poco, el fraile le descubrió sus intenciones: nada menos que cambiar la Arcadia feliz ilustrada por un "Fraternum Foedus" o "Marianum Foedus", algo así como "una mezcla de sociedad comercial, caja de ahorros y compañía de seguros", según la expresión de M. Defourneaux, bajo la invocación mariana: el colmo para Olavide, que ni podía imaginar lo que el capuchino tramaba contra él ${ }^{17}$.

Tras la llegada del fraile, el clima de hostilidad entre los colonos fue in crescendo, más al saber que se ridiculizaban sus propuestas chez Olavide, y que en las animadas tertulias, el superintendente y sus amigos se reían abiertamente del barbudo suizo. Pero pronto, las risas iniciales de los amigos de Olavide fueron cambiando por el gesto preocupado. Al principio, según declaró luego el reo Olavide, "nos divertíamos con descubrir su ignorancia (la de Fray Romualdo), y con los disparates y absurdos que decía"18, pero el fraile no reía, ...escribía. Cuando se dieron cuenta de la gravedad de los hechos, ya era tarde.

Mientras se frivolizaba en el palacio de La Carolina sobre supersticiones y absurdos de ciertas prácticas religiosas, el fraile suizo iba escribiendo folios y folios con detalles de la vida diaria de Olavide, escandalizándose y exagerando, y los dirigió en todas las direcciones, incluyendo entre los destinatarios a los obispos de Jaén y Sevilla. Asombrado de que Olavide tuviera apoyos incluso entre los prelados, dirigió sus dardos más arriba: a Madrid. Tras mucho intentarlo, Fray Romualdo se salió con la suya y al fin, en 1775, sus denuncias llegaban a los inquisidores de corte y al temible padre Eleta.

En un momento tan agitado políticamente -ya lo hemos visto antes-, el confesor de Carlos III tenía en sus manos el retrato perfecto del vividor, del deísta, del corrompido: la más detallada descripción del espíritu de un hombre libre, que nada tenía que temer de un Dios a su semejanza, inmensamente bueno y comprensivo. Y junto a ese retrato, tenía también los rumores, difundidos por toda Europa, que celebraban el fin de la Inquisición: "Aranda merece el reco-

17. Defourneaux, Pablo de Olavide, 1990. Según un panfleto "consegnato al nunzio un anno prima che si decidesse la causa da un stretto parenti del detto Olavide", el proyecto del fraile era muy otro: "perderlo para quedarse él señoreando la colonia o a lo menos poder disponer que los principales frutos de ella se trasladasen a Alemania por medio de hacer venir de allá hombres que se estableciesen y enriqueciesen con las producciones de la colonia y que después se pasasen a su tierra con cuanto hubiesen adquirido (...). Así se lo proponía al embajador de aquella corte asegurándole que para acabar con D. Pablo de Olavide tenía ya dados pasos y que una representación que había hecho a una persona de alta clase y dignidad (que nombra) muy inmediata a SM le había salido tan bellamente que había producido efecto", Noticia de los sucesos de D. Pablo de Olavide, Archivo Secreto Vaticano (en adelante ASV), Archivio Nunziatura Madrid, 177.

18. AHN, Inquisición, leg. 1866-2. Olavide al vicario Lanes, copia sin fecha, pero de 1776. 
nocimiento de Europa entera al cortar las garras y limar los dientes del monstruo", había escrito Federico a Voltaire. El propio rey, santurrón, terco y celoso de sus prerrogativas, entre ellas, gobernar la Inquisición, iba a utilizar a Olavide para demostrar lo contrario: que el Santo Oficio no sólo no había desaparecido, sino que era necesario. En ello le iban a ayudar el padre confesor Eleta y el sinuoso y "librepensador" ministro de Gracia y Justicia, Manuel de Roda ${ }^{19}$.

\section{Olavide, víctima}

Seguramente, el plan inquisitorial estaba trazado ya cuando Su Majestad ordenó a Olavide trasladarse a Madrid, en noviembre de 1775, "para tratar negocios de su Real Servicio". Nada más leer la orden del rey, Olavide intuyó la gravedad del asunto -seguramente, también recibió algunas informaciones a través de Grimaldi- y abandonó sus queridas Poblaciones en diciembre de 1775 para instalarse en Madrid, en casa de su cuñado Luis Urbina, donde empezó a preparar su defensa. Consciente del peligro, pensó en todos los frentes, incluso en el teatral, en la exhibición de una vida religiosa, apartada de licencias y diversiones. Se deshizo de libros prohibidos, adquirió otros de oraciones y santos, no olvidó el rosario en su atuendo -estaba acusado de reírse de esa devoción-, ni el escapulario de la virgen del Carmen, que ya no se quitó del pecho. En el frente político, Olavide corrió a ofrecer su versión a todos sus amigos, pero se vio abandonado. Aranda, embajador en París, no dijo nada; además, el conde aragonés se había enemistado con Grimaldi, el último valedor de Olavide, al culparle del desastre de Argel: el capitán general Aranda era ante todo un militar que tomó, como el rey, la derrota frente a los moros como un escándalo vergonzante. Pero, para entonces, Aranda estaba ya enemistado con el rey y marginado de los asuntos políticos.

Olavide debía intentarlo con quienes estaban en el poder -en la confianza regia- en ese momento: el inquisidor Felipe Beltrán y el ministro de Gracia y Justicia, Manuel de Roda. Pero también en lo más alto del poder había que protegerse -como hacía Campomanes, por ejemplo-, pues había nuevos focos de tensión, y algunos afectaban al rey en persona. No era un buen momento para Carlos III. Coincidían muchos problemas en una cabeza - regia- tan escasa de luces. La derrota de Argel fomentó la discordia entre los ministros, se prepara-

19. El marqués de La Corona decía sobre el hipócrita Roda: "Acuérdome de haber oído al P. Confesor (...) cuando se dudaba mucho de que se lograse la extinción de los jesuitas, y aún llegaba a temerse que volvieran, estas precisas palabras: "tal arte tiene este hombre de esconderse en lo que tiene más parte y aún en lo que sea enteramente obra suya como perciba desde lejos el más remoto peligro, que si se volviera a examinar el asunto de Jesuitas y los que habían tenido parte en su expulsión, no se encontraría una esquela ni un dedo de papel suyo. El Consejo Extraordinario, el confesor, ciertos sujetos y prelados y el rey mismo serían los que tendrían que responder y él se quedaría muy tapado y encubierto como que nada había hecho, habiendo sido el alma de todo cuanto se hizo". AHN, Estado, leg. 3211-2. 
ba el matrimonio morganático del infante Luis -un asunto escandaloso en el que salía a relucir la peor bilis de Carlos III-, caía el gran Tanucci en Nápoles, y se rumoreaba que la Inquisición volvía por sus fueros ${ }^{20}$. No han de extrañar las palabras de Pietro Giusti, un veneciano al servicio de la embajada austriaca en Madrid, que indicaba por estas fechas que las luces penetraban en España "con maggiore difficoltà e lentezza" y que definía al país como "produttrice d'ingegni profondi e naturalmente giusti, ma ritenuti nell'inazione non dall'influenza del clima, come si declama da alcuni e si copia dagli altri, ma dal dispotismo religioso e politico e dalla cattiva legislazione" ${ }^{\prime 21}$.

A nadie le sorprendía la situación terrible de Olavide, ni a sus amigos ni a él mismo, que incrementó si cabe las medidas de protección: en un golpe de audacia, se presentó, el 12 de febrero, ante el mismísimo inquisidor, con el que se sinceró como católico y pecador arrepentido. Pensó que la jugada no podía fallar: Felipe Beltrán, que llegó al cargo precedido de muy buena fama como prelado ilustrado, debería entenderle, como le entendían muchos obispos y curas andaluces cuando hablaba -en serio- de asuntos de religión y conciencia. Él era un verdadero católico.

La visita nocturna y sorpresiva de Olavide sorprendió al Inquisidor Beltrán, que le decía a Roda el 14 de febrero de 1776: "me he visto en la mayor confusión porque (Olavide) se me presentó anteanoche y me detuvo dos horas en conversación sin saber yo qué responderle". Beltrán notó que "está muy inquieto y se le remuerde mucho la conciencia" lo que le llevó a pensar que "teme mucho". El obispo añadía con una sospechosa seguridad: "y con razón". Era evidente que Beltrán, que le decía a Roda "siento que tenga noticia tan cierta de la delación como supone", no era el padre capaz de perdonar, lo que debió intuir Olavide, que ya había escrito directamente al ministro una semana antes ${ }^{22}$.

Olavide se sinceró, por escrito, ante Roda, justificando su posición de verdadero católico con argumentos de peso. La preciosa carta de 7 de febrero -ciertamente, una declaración exacerbada de fe católica- no iba dirigida sólo a su destinatario, el ministro "librepensador" y arandista; es evidente que Olavide quería que fuera leída también por Carlos III, el único que ya a esas alturas podía parar la maquinaria inquisitorial. Por eso, Olavide, que sabía que el rey "le oye (a Roda) años ha todas las mañanas en conversación familiar", terminaba suplicando al ministro: "Dirija V. E. a quien busca sus luces", es decir, al rey. Olavide confiaba todavía ...jen las luces y en el rey! ${ }^{23}$

20. Véase Rafael Olaechea, "Información y acción política: el conde de Aranda", Investigaciones históricas: época moderna y contemporánea 7 (1987), 123-124.

21. Pietro Giusti a Cesare Beccaria, 12 de enero de 1775, Beccaria, Dei delitti, 567.

22. AGS, Gracia y Justicia, leg. 628. Felipe Beltrán a Roda, 27 y 29 de enero, y 14 de febrero de 1776 .

23. AGS, Gracia y Justicia, leg. 628. Olavide a Roda, 7 de febrero 1776. La carta reproducida en Ferrer del Río, Historia del reinado, vol. III, 47, que dice que es "de imposible lectura 
Mientras tanto, la Inquisición siguió recabando declaraciones de testigos -hasta 78- con las que, al fin, pudo llegar a la terrible conclusión del 14 de septiembre de 1776: "que este sujeto sea preso en las cárceles secretas deste Santo Oficio, con secuestro de todos sus bienes, libros y papeles, y se siga su causa hasta definitiva", lo que se cumplió justo dos meses después, el 14 de noviembre de ese año, no sin antes haber obtenido el inquisidor Beltrán el plácet de Carlos III, a quien se lo pidió el 29 de octubre ${ }^{24}$. Nada se podía hacer sin la aquiescencia del rey, sobre todo cuando estaba en juego la suerte de uno de sus primeros ministros.

Así, con el consentimiento del rey, el 14 de noviembre de 1776, a las seis de la tarde, Olavide entraba en las cárceles secretas de Madrid.

\section{Olavide, instrumento}

Muchos historiadores se han dejado engañar por Ferrer del Río, el decimonónico panegirista de Carlos III, que conduce a Olavide directamente al "autiIlo" el 24 de noviembre de 1776, ahorrándole dos años de terrible prisión incomunicada ${ }^{25}$. Errata, lapsus o intención de exculpar al rey ilustrado, lo cierto es que incluso Menéndez Pelayo silenció estos dos años de "desaparición" y que todavía hoy, en obras recientes, se mantiene el error. Es verdaderamente sorprendente pues la documentación sobre estos dos años de prisión es abundante. Hay cartas de la familia -tanto en el AHN como en Simancas-, reclamaciones patéticas, pues la familia de Olavide ni siquiera sabía si el preso estaba vivo. La mujer de Olavide, Isabel, y su cuñado, Luis Urbina, escribieron constantemente a Carlos III durante esos dos años, aprovechando fechas como la Navidad, tocando todas las teclas de la regia piedad: "el corazón de V.M. es tan pío, tan dulce, tan benigno como tiene acreditada la experiencia", "Ilegaría día en que V.M. derramase sobre él sus piedades", "para todo tiene V.M. clemencia", etc. Son cartas largas, dramáticas, duras las de Urbina exigiendo a Roda que se viera de una vez la causa y cesara la situación irregular del inocente. Al final, los familiares comprendieron el silencio regio, dudaron del

sin que a la vez se apoderen del ánimo el enternecimiento y la congoja", tal es el patetismo con que Olavide la escribió.

24. Los detalles sobre cargos, testigos, presiones, etc., magistralmente expuestas en Defourneaux, Pablo de Olavide, capítulos IX y X. Sobre la actuación de Beltrán, especialmente su solicitud al rey para que aprobara la prisión secreta, AGS, Gracia y Justicia, leg. 628, Felipe Beltrán al rey, 29 de octubre de 1776.

25. Ferrer del Río, Historia del reinado, vol. III, 53. No así Coxe, que refleja la prisión: “Después de dos años de reclusión en un oscuro calabozo, se terminó por fin, la causa, y anunciada la sentencia públicamente", William Coxe, España bajo el reinado de la casa de Borbón, (Madrid: Salas y Quiroga, 1846), vol. VI, 245. Pero el error es tenaz: véase la, por otra parte, excelente publicación Carlos III y su época (Barcelona: Carroggio, 2003). En el voluminoso libro se puede leer cómo Olavide estuvo preso ocho años en La Mancha, o cómo "fue condenado en 1776 a la confiscación de sus bienes...", o cómo "se fugó sin grandes problemas". 
ministro - demasiado tarde- y sólo pidieron que la causa se viera cuanto antes para que un inocente Olavide pudiera defenderse. Mientras, el prisionero sufría lo indecible en el lóbrego y frío calabozo, en el que le habían encerrado, sin criado -se lo cambiaron por un espía-, sin luz y sin estufa, que le retiraron por temor a que provocara fuego. Las piernas se le hincharon, engordó exageradamente, casi enloqueció. Sin embargo, nadie movió un dedo ${ }^{26}$.

El efecto en toda Europa fue extraordinario: la Inquisición volvía a cebarse con una víctima. Pero nadie dijo nada fuera de los salones ilustrados. Aranda se volvió mudo. El aragonés, embajador en París, era irreconocible con respecto al que fue años atrás cuando pregonaba a los cuatro vientos que era "interés de la clerecía y frailería tener un tribunal semejante, con que intimidar a los seculares y con que prohibir cuanto pueda abrirles los ojos" o que "si en Italia, y aún Roma, no está la Inquisición en el absoluto poder que en España, por qué lo ha de estar en ésta". Todo el mundo podría recordar que había Ilamado "borricos" a todos los "condiscípulos" de los miembros del Consejo de Castilla que "han sido en todo tiempo destinados para inquisidores" ${ }^{27}$. Azara, que lloraba "lágrimas de sangre" según le decía a su amigo Roda, se dolía de que todavía ocurrieran cosas así en España ${ }^{28}$. Pero todos sabían por qué callaron. Años después, algunos que habían hablado en París con el conde de Aranda dijeron lo que éste pensaba: el embajador no calló por temor a la Inquisición, sino por temor a Carlos III, a cuya "opiniâtreté et bigoterie" atribuyó certeramente la desgracia de su antiguo amigo ${ }^{29}$. El conde y sus más próximos sabían que el rey santurrón era capaz de ir mucho más allá. Por eso dejaron que hubiera ...una sola víctima ${ }^{30}$.

Y es que el rey no sólo estuvo informado en todo momento, sino que dirigió la acción y los actores. Una prueba de su interés personal es que cuando la Inquisición de Sevilla procedía a plena luz del día a "los embargos de todos los bienes que tiene don Pablo de Olavide en su alojamiento situado en los reales alcázares", el rey se negó a hacer cesar los alborotos públicos que organizaban los que celebraban la ruina del superintendente, también Asistente de Sevilla,

26. Las cartas, en AGS, Gracia y Justicia, leg. 628. También las respuestas de Roda, evasivas. Véase un ejemplo: "Y habiendo dado cuenta al rey de este memorial me ha mandado S.M. pasarle a manos de V.I. como de su real orden lo ejecuto para que haga de él el uso que estime conveniente". Con el consiguiente silencio de Beltrán.

27. Aranda a Wall, Varsovia, 28 de noviembre de 1761, AGS, Estado, Libro 154.

28. "¿Es posible que se vean aún cosas como la que acaban de hacer con Olavide? Yo no soy su amigo, pero la humanidad me hace llorar lágrimas de sangre", J. Nicolás de AZARA, El Espíritu de Azara descubierto en su correspondencia epistolar con D. Manuel de Roda (Madrid: Imprenta de J. Martín Alegría, 1846), vol. III, 57-58.

29. Lautico García, Francisco de Miranda y el Antiguo Régimen español (Caracas: Universidad Pontificia Gregoriana, 1961), p. 362.

30. Olaechea, "Información y acción política", 81-130; ver también su deliciosa obrita Viajeros españoles del XVIII en los balnearios del Alto Pirineo francés (Logroño: Colegio Universitario de La Rioja, 1985). 
donde había intentado la reforma de su universidad y fomentado el teatro, ganándose la inquina de los clérigos. Antes al contrario, el rey terció personalmente. Lo sabemos por carta de 5 de diciembre de 1776, de Beltrán al ministro: "enterado Su Majestad,... se ha servido resolver que no sólo no impida las diligencias que intente practicar el tribunal de la Inquisición sino es que le auxilie en todos sus procedimientos ${ }^{\prime \prime 3}$. Desde el primer momento el rey había tomado partido contra la víctima.

Así, la actitud regia permitía que el caso Olavide siguiera provocando escándalo y que los frailes sevillanos festejaran a sus anchas la caída del que vieron siempre como al mismísimo demonio. Como escribió Bourgoing, los frailes "se entregaban a todos los excesos del celo, declamando su furor contra los teatros profanos que Olavide había tratado de mejorar en esta ciudad. Al mismo tiempo, los inquisidores de provincias compartían el triunfo de esta capital y hacían ostentación de sus fuerzas renacidas" ${ }^{\prime 2}$.

\section{La pena y el desengaño: Olavide, católico}

Pasados dos años de silencio con el preso en cárcel secreta, se encontró al fin una solución para el "desaparecido", lo que no fue nada fácil: si el reo era un hereje formal debía correr la misma suerte que miles de españoles que perdieron la vida por ello; si no, debería buscarse la fórmula para justificar nada menos que dos años de prisión. Además, todo debía verse en acto público, con el riesgo de que el reo se mostrara convincente y el escándalo fuera mayor: todos sabían que tenía amigos y que, en Europa, el caso había sido tema de conversación en todas las cortes. Por todo ello, se buscó la fórmula del autillo, un acto público reservado, en el que se exhibiría teatralmente la sentencia, pactada de antemano, todo a gusto de Su Majestad... Ilustrada.

El autillo se celebró el 24 de noviembre de 1778, pero la maquinaria se había puesto antes en marcha, antes incluso del día 11 de noviembre -trece días antes del autillo-, cuando el inquisidor Beltrán, "en obedecimiento de lo que Vuestra Majestad tiene dispuesto y mandado en este punto" -una vez más, sumiso y prudente-, comunicaba al rey que "da curso a este negocio", y añadía que, además de "ponerlo en la superior inteligencia de la Real Persona", iba a "consultar la resolución y sentencia que se hubiese acordado". Más claro no se puede hablar: el inquisidor sometía su voluntad -y la del tribunal-al rey, que es el que ordenó incluso la fecha de comienzo del "negocio" ${ }^{33}$.

31. AGS, Gracia y Justicia, leg. 268. Bruna a Grimaldi, 20 de noviembre de 1776, dando cuenta del "escándalo", y Beltrán a Roda, 5 de diciembre de 1776. Defourneaux, que intentó evitar en lo posible la responsabilidad de Carlos III, no quiere enterarse de que se dice claramente en la carta: Su Majestad "se ha servido resolver..."

32. Cit. en Defourneaux, Pablo de Olavide, 502.

33. AGS, Gracia y Justicia, leg. 628. Defourneaux tampoco menciona estas declaraciones del inquisidor. 
Por el embajador francés sabemos que Beltrán visitó al rey tres días antes del autillo "para recibir órdenes sobre el particular". Desde luego, no se le ocultaba que "el fallo de este caso no se ha pronunciado sin antes haberlo sometido a examen de Su Majestad", como trasmitió a su corte ${ }^{34}$. El propio Inquisidor dejó ver nuevos indicios cuando el 26 de noviembre escribió a Roda que el auto del 24 "es el que se acordó con Su Majestad y Vuestra Excelencia lo sabe" ${ }^{\prime 35}$. Luego, Beltrán se disculpaba -¿de qué?- y lanzaba la siguiente justificación: "este lance me enfermó a causa de la condición de mi genio, me hizo pasar dos noches sin cuasi poder pegar los ojos y me dejó sin cabeza para nada" ${ }^{136}$.

Es extraño: el inquisidor sufría, y sin embargo, no se conmiseraba con el reo, pues aún escribía que "no está verdaderamente arrepentido". ¿Por qué sufría si ya conocía cuál iba a ser el resultado? ¿o es que tuvo que emplearse a fondo para evitar que el "hereje y miembro podrido" fuera condenado a muerte como mandaba la ortodoxia inquisitorial? Quizás fue esa lucha la que le "enfermó", pues no pudo estar tranquilo hasta conocer la real gana del rey. Con todo, el que todavía pasa por bondadoso Beltrán pudo tranquilizarse pronto: sabía que Olavide había estado Ilorando por la mañana -al día siguiente del autillo-, pero que "ya cenó muy bien" por la noche. Y tergiversando la idea de la esposa del reo, que decía que su marido, infamado, no tendría más remedio que salir de España, Beltrán anunciaba a Roda: "mucho me temo que puesto en libertad se ha de pasar a provincias extranjeras en que se permite sentir libremente y como a cada uno se le antoja de las cosas de religión y $\mathrm{fe}^{\prime \prime 37}$. En cualquier caso, Olavide había salvado la vida.

La parte pública de la condena de Olavide es bastante conocida a pesar de que no se conserva documentación original del acto. Hay muchas relaciones, descripciones del autillo en muchas copias, que coinciden en lo importante, en la comparecencia del "desaparecido" el 24 de noviembre de 1778, a las ocho de la mañana, hora a que comenzaba una sesión agotadora... ${ }^{38}$ Como "los autos de fe se celebran todavía en el tribunal de la inquisición con mayor o menor publicidad, conforme a la impresión que se desea producir", según le dijo a Coxe un testigo, el autillo, un auto de fe a puerta cerrada con "invitados", cumplía el objetivo del escarmiento, pues era a los "amigos de Olavide" presentes en

34. Defourneaux, Pablo de Olavide, 506. Es difícil entender hoy por qué, a la vista de tantas pruebas, el célebre historiador francés no inculpó al rey. Tampoco lo hizo del todo R. Olaechea, a pesar de sus sospechas.

35. Defourneaux copia parte del texto pero suprime esta frase. Defourneaux, Pablo de Olavide, 506, 52.

36. La interesante carta completa en AGS, Gracia y Justicia, leg. 628.

37. AGS, Gracia y Justicia, leg. 628.

38. Una de las descripciones menos conocidas, Olaechea, Viajeros, 1995. Las clásicas, por ejemplo, Biblioteca Nacional (en adelante BN), Manuscritos, 11.089. Breve y compendiosa noticia...; V. Castañeda, "Relación del auto de fe en el que se condenó a D. Pablo de Olavide", Revista de Archivos, Bibliotecas y Museos XX (1916). 
la sala a los que estaba dirigida la lección, tanto a los libertinos, enciclopedistas, deístas, etc., como a los que pudieran pensar en reformar los arcanos del rey.

En medio de ese concurso ilustrado, salió Pablo de Olavide, vestido de paño pardo, sin la insignia de la orden de Santiago -ya estaba degradado-, también sin el Sambenito y el Aspa de San Andrés, por dispensa de Beltrán, pero sí con la infamante vela verde en la mano. Bourgoing dijo que el reo se "permitió varias burlas intempestivas", pero debieron informarle mal, pues todos los escritos que cuentan la vista coinciden en lo terrible de un "acto estremecedor". El secretario tardó varias horas en leer el compendio de los más de 170 artículos que contenía la causa, así como algunas pruebas, entre ellas la conocida carta de presentación de Voltaire "Va don Pablo de Olavide, hombre que sabe pensar"... Por la sala resonaron, en solemnes palabras de clérigo altivo, los excesos, libertinajes, opiniones libres -contra los frailes, contra el matrimonio, contra el rosario-, las burlas sobre las reliquias, los detalles extraídos de las declaraciones de 78 testigos, casi todas recordando las originarias, las que el temible Fray Romualdo había compilado en cientos de folios. En realidad se trataba de asuntos de costumbres y de opinión, delitos en realidad menores contra los que Olavide estaba bien preparado; aunque fuera muy altisonante acusarle de leer libros prohibidos o de burlarse de los frailes, por ello no sería condenado más que a reparar el daño mediante la oración. Bastaría implorar penitencia para ablandar la pena.

Por eso, cuando el secretario comenzó a leer las conclusiones y Olavide oyó que se le acusaba de "hereje formal y miembro podrido de la religión", cayó al suelo casi desvanecido después de decir "no, eso no". El reo sabía perfectamente lo que acarreaba esa acusación: era pena de muerte.

Antes incluso de pronunciar sentencia, el tribunal había escenificado su gran triunfo, la última demostración de su utilidad -precisamente lo que algunos venían poniendo en duda desde hacía mucho tiempo-, pues don Pablo, después de "reconciliado con toda la formalidad que previenen los sagrados cánones", azotado en la espalda por cuatro sacerdotes "durante el Miserere", "hizo la protestación de la fe, bañado en lágrimas, por lo que se creyó en aquel entonces un buen concepto de su arrepentimiento". El Santo Tribunal había logrado devolver a la Iglesia a un miembro ...descarriado; y para mayor gloria del rey ilustrado, se había producido sin piras y sin torturas.

Pero de ningún modo puede considerarse el castigo infligido a Olavide como poco severo (lo que ha sido recurrente en la historiografía) ${ }^{39}$. Tras pasar dos terribles años "desaparecido" en las cárceles secretas, Olavide quedaba privado de todos sus honores e inhabilitado perpetuamente, desterrado de Madrid,

39. Sobre la dureza del castigo, Coxe pensó lo que muchos entonces: "por riguroso que parezca este castigo, es todavía muy suave comparado con la severidad desplegada en otros tiempos por la inquisición para castigar esta clase de ofrendas". Coxe, España bajo, vol. IV, 247. 
Sitios Reales, Nuevas Poblaciones y Lima, y obligado a vestir de "paño común". Además, debería estar en un convento durante ocho años, bajo un director "que le enseñe y fortifique en Doctrina Cristiana", rezando el rosario diariamente y leyendo la Guía de Pecadores de Fray Luis de Granada, mientras todos sus bienes eran confiscados. Es extraño que haya habido tanta unanimidad en considerar una pena de dos años en la cárcel secreta y ocho años en un convento como una "sentencia blanda" 40 .

El primer destino del condenado fue el convento de los benedictinos de Sahagún, en la fría provincia de León, donde pasó el gélido invierno hasta que, en junio de 1779, le trasladaron al convento de capuchinos de Murcia, previo paso por la estación termal de Puertollano y una breve estancia en Almagro. Una vez en Murcia, las penalidades eran las contrarias: la habitación del reo era sofocante, en un segundo piso bajo tejado. El 29 de agosto de 1780, Olavide escribía a Beltrán: "yo me estoy muriendo, no puedo curarme aquí, las enfermedades que padezco son graves y prolijas". El preso mostraba síntomas de escorbuto, el cuerpo se le había hinchado de nuevo y hasta había momentos de pérdida de la razón. En la carta citada, Olavide concluía: "La piedad del santo Oficio no me ha condenado a muerte sino a penitencia y no es, señor, poca la que he hecho y la que hago" ${ }^{\prime 4}$.

Los médicos pensaron que de nuevo debía probar aguas sulfurosas, y que le convenían más las de Caldets (Caldas de Montbui) en Gerona, a donde Olavide se encaminó en octubre de 1780 tras recibir permiso del Inquisidor Beltrán. Quizás en este momento Olavide empezó a pensar en la fuga. Aunque se ha dicho que fue facilitada desde arriba, no es cierto $^{42}$. Como mucho, pudo haber una cierta candidez del inquisidor, que dio el permiso para que el preso se trasladara a un lugar tan próximo a la frontera, pero no hay prueba alguna de connivencia del gobierno, y menos aún de Carlos III. Olavide no era ya un escándalo, sino un penitente; ni siquiera estaba bajo jurisdicción civil ${ }^{43}$.

40. Un ejemplo, nuestro querido maestro, recientemente fallecido, Antonio Domínguez Ortiz, Sociedad y Estado en el siglo XVIII español (Barcelona: Ariel, 1976), 366. Quizás pensaba también lo que ya insinuó Coxe (nota anterior). Muchos han opinado sobre el particular, véase Juan Antonio Llorente, Historia crítica de la Inquisición en España (Madrid: Hiperión, 1980), vol. V, 310: Manuel de Godoy, Memorias, (Madrid: Biblioteca de Autores Españoles, 1965), vol. I, 191.

41. AHN, Inquisición, leg. 1866-4, varias cartas entre Olavide y Beltrán. Ésta de 29 de agosto de 1780 .

42. La idea, procedente de Defourneaux, ha sido puesta en duda por A. Cascales, "La evasión de Pablo de Olavide a Francia. Algunas matizaciones a la hipótesis de la negligencia programada", Archivo Hispalense 71 (1988), 61-69. La revisión de la documentación mueve a pensar que, en efecto, nadie ayudó al condenado. Ni él, enfermo, ni su mujer, octogenaria, parecían capaces de fugarse, así que simplemente la vigilancia cedió de manera natural.

43. Las cartas de Olavide a Beltrán, en AHN, Inquisición, leg. 1866-4, muestran la constancia del condenado en conseguir salir de Murcia, pero tal es el tono que no es probable que Beltrán pensara que Olavide utilizaría su permiso para facilitar su fuga. 
Sólo cuando pasó la frontera, volvió a suscitar interés en los ministros de CarIos III, que, efectivamente, respondieron como era su deber: solicitando a Francia la extradición del prófugo. Floridablanca, por orden del rey, escribió a Aranda, y éste al ministro Vergennes, que se desentendió diplomáticamente diciendo que Olavide no había cometido delito alguno en Francia. El todavía embajador Aranda hubo de comunicar a Floridablanca que el ministro francés le había dicho que si Olavide transgredía alguna ley francesa, no dudara en que la justicia francesa le perseguiría ${ }^{44}$. Parecía una broma: quizás lo era. Pero no convenía airear el caso y llamar la atención de la Europa ilustrada. Todos sabían que en ese momento, la víctima de la Inquisición, en realidad un pobre hombre enfermo de 56 años, y su mujer octogenaria, Ilegaban a París tras pasar unas semanas en Ginebra, y que en los salones de la capital del Sena se celebraría de nuevo que una víctima española se hubiera librado de la hidra inquisitorial que, a diferencia de lo que se pensaba unos años antes, no estaba tan inactiva.

\section{Olavide, en Francia}

Olavide vivió en Francia una vida acomodada - había pasado antes a París buena parte de sus riquezas-, haciéndose conocer como conde de Pilos y frecuentando los salones ilustrados de sus amigos, en los que seguía fascinando por su chispeante conversación. Volvía a ser el hombre de moda, ahora en su adorada Francia. Hasta la emperatriz Catalina II se enteró -por carta de Grimque Olavide había pasado por Ferney -los "sagrados lugares" - antes de llegar a París: "se ha emocionado allí hasta caerle las lágrimas al ver hasta qué punto la memoria del gran patriarca (Voltaire) es reverenciada (...) Este relato - del propio Olavide a Grim- me ha hecho caer lágrimas, aún cuando yo no he sido víctima de la Inquisición" ${ }^{\prime 4}$.

Con todo, Olavide fue discreto y no explotó su bien ganada fama, quizás porque también en Francia las cosas estaban cambiando. La propia Catalina II, en contestación a la carta de Grim, decía: "Voltaire no tiene tantos entusiastas después de su muerte como vivo los tuvo" ${ }^{46}$. En cualquier caso, Olavide fue retrayéndose del trato social, limitándolo a sus amigos aristócratas, especialmente Dufort de Cheverny, al punto de que la Correspondance de París decía: "hoy pasa en París días tranquilos (...), perdonando como buen cristiano a los capuchinos y a los inquisidores, tratando de olvidar..."; pero también recordaba que vivía "en medio de nuestros espectáculos, de nuestros filósofos...", mientras Dufort, en sus Memorias, escribía que seguía conservando "el atractivo y seducción de que tan frecuentemente se sirviera", aunque "la pasión a

44. La correspondencia entre los ministros, en AHN, Inquisición, leg. 1866-3.

45. DEFOURNEAUX, M., op. cit., p. 521.

46. Ibid. 
veces excesiva que animaba tiempo atrás sus discusiones se ha transformado en mesura y afabilidad" ${ }^{\prime 4}$.

Aún así, a todos sorprendía la insaciable curiosidad de Olavide y lo pendiente que estaba de las cosas de España; también de que le Ilegara tabaco español. Los bolsillos de su chaqueta eran una tabaquera, según el comentario despectivo de Madame Vigée-Lebrum. Esta aristócrata lo encontró en 1788, invitado en la Malmaison, donde "había tenido la ocurrencia de mandar colocar (...) una inscripción que decía 'Sierra Morena'"; también estaba allí "la señora Cabarrús, mujer del fundador del Banco de San Carlos, que trabaja por regenerar a España con el mismo celo y optimismo con que en otro tiempo lo hiciera Olavide" ${ }^{\prime \prime}$.

La misma curiosidad mostró Olavide por los acontecimientos revolucionarios que, de nuevo, le colocaron en una situación privilegiada ${ }^{49}$ : la de los extranjeros adictos. Por más que su papel no fuera nunca protagonista, fue testigo directo en los grandes escenarios: vivió en Versalles mientras estuvo reunida allí la Asamblea de Notables; se trasladó a París cuando lo hizo el rey; seguramente, asistió, como integrante de la "Delegación de Proscritos" a la Asamblea Constituyente, y hasta pudo ser nombrado "ciudadano adoptivo de la República", pero todos estos actos contrastan con su propia declaración en El Evangelio en triunfo -la controvertida obra que iba a empezar a escribir poco despuésy con lo que pronto Ilamó la atención a todos. Como le ocurrió a su amigo Dufort, que se horrorizó desde un principio por la "anarquía", Olavide, según un amigo de uno de sus protectores, "se ha hecho devoto hasta un grado asombroso y con toda la beatería de la iglesia romana"50.

Sin embargo, de nuevo, es el propio Olavide quien siembra la duda sobre su proceder. En el prólogo de El evangelio..., declara: "yo fui testigo de sus primeros trágicos sucesos (de la "espantosa revolución"), y viendo que cada día se encrespaban más las pasiones y anunciaban desgracias más funestas, me retiré a un lugar de corta población" ${ }^{\prime \prime 5}$. Pero -era de esperar-Olavide no se sincera del todo. Es cierto que se retiró a Meung sur Loire, al campo, pero no lo hizo hasta octubre de 1791, cuando él y sus amigos aristócratas ya no podían sentirse seguros.

Atrás quedaban los días hermosos en que Luis XVI era ensalzado como ciudadano ejemplar, con el concurso de los privilegiados -Olavide entre ellos-, que aplaudían al rey "restaurador de la libertad francesa". Quizás si a esto no hubiera seguido el proceso de descristianización, Olavide hubiera seguido

47. Ibid., p. 306.

48. Ibid., p. 313.

49. DUFOUR, G., "Olavide y la revolución francesa", Estudios de historia social, 36-37, (1986), pp. 77-80.

50. Cit. en DEFOURNEAUX, M., op. cit., p. 317.

51. El Evangelio..., prólogo. Citamos de la reciente edición publicada en Oviedo por la Fundación Gustavo Bueno. 
viviendo su dulce y piadoso exilio, pero en pocos meses todo cambió. Son seguras sus constantes muestras de piedad, pero cuando se vio en peligro frente al terror de la Convención, en 1793, Olavide tuvo que ingeniárselas, una vez más, para evitar una nueva desgracia, declarando su ardor patriótico y republicano: blasonó de ser fundador de la Societé populaire, de contribuir con un "donativo patriótico", de haberse alistado en la Guardia Nacional y de haber "huido con horror de aquella tierra de opresión y de tiranía para venir a vivir en la tierra de la Igualdad y de la Libertad".

Esto no lo decía ni en El Evangelio... ni en la carta remitida a Carlos IV. Aquí sólo aparecía su tragedia: la prisión que sufrió. Nada dice de lo que tuvieron que declarar, para salvarle, los ciudadanos de Meung, que se hicieron oír ante el Comité de Salud Pública, confirmando las virtudes patrióticas de un Olavide, "ciudadano francés que debe gozar de todos los beneficios y derechos inherentes". Había sido apresado como enemigo, por estar España en guerra contra la Convención, pero quedaba probado que su actitud era la de un "buen patriota y amigo celoso entre los más de la República, una e indivisible". Fue puesto en libertad a la vez que caía Robespierre.

Tras su liberación, pasó un año en Meung y se trasladó, con su amigo Dufort y con su capellán, el abate Renard, al castillo de Cheverny, donde empezó a escribir El Evangelio en Triunfo, o mejor dicho, .... a traducir. Como ya sabemos, sólo la última parte revela al Olavide ilustrado de otros tiempos, pendiente de las cosas de España y nostálgico de esa idealizada "Sierra Morena" que se había hecho poner en el cartel de la Malmaison. Quizás su amigo Dufort pensó en esta parte del libro cuando dijo que todo salió de su "cabeza bien dotada y de su imaginación fecunda", sin tener que consultar libros, utilizando sólo los "prodigiosos recursos de su memoria y de su inteligencia".

Sin embargo, lo más asombroso de este último Olavide es que -igenio y figura!- El Evangelio en triunfo es "la obra más impersonal que se pueda imaginar". Como ha demostrado G. Dufour, no es que Olavide tuviera en cuenta algunas obras francesas a la hora de escribir su obra, como declara en el prólogo -por ejemplo, Les delices de la Religión ou le Pouvoir de l'Evangile pour nous rendre heureux, del abate Lamourette, de la que copia textos completos -lo que ya se sabía ${ }^{52}$-, sino que el fundamento de la obra, las discusiones del Religioso y el Filósofo, "no son sino la traducción precisa de la obra maestra del abate Houteville, La Religion Chrétienne prouvée par les faits"153, editada en París, en 1765. Todas las coincidencias aparentes entre la vida de Olavide y el incrédulo corre-

52. Según refiere H. CH. Lea, un diputado de la cortes de Cádiz, que había visitado a Olavide en Baeza, reveló que Olavide había copiado a Lamourette en El Evangelio. LEA, C. CH., A history of the Inquisition of Spain, New York, 1907, vol IV, p. 308. Defourneaux lo divulgó luego, sin atribuir la totalidad a la traducción. Véase también el prólogo de E. NúÑ̃Z en Obras narrativas desconocidas de Olavide, en www.cervantesvirtual.com.

53. DUFOUR, G., Cartas..., p. 8. 
gido por el religioso que al final se arrepiente y descubre la vida sencilla, premiada con el encuentro del amigo que creía muerto, no son más que un feliz hallazgo literario al que Olavide llevó poco más que su conocida habilidad de traductor (aunque los muchos años pasados en Francia se notaban en los numerosos galicismos de la obra). Sólo las cartas de Mariano a Antonio, que ocupan casi todo el tomo IV de la edición princeps de Valencia, contienen ideas originales de Olavide, aunque muy retocadas para evitar problemas con la censura. El grueso de la obra son sólo textos traducidos perfectamente identificados.

\section{El Evangelio en triunfo}

Al final, la solución del problema universal -creer o no creer- no está en la exhibición de comportamientos individuales ejemplares, ni en lo aparente de las conciencias ajenas vencidas, por mucho que la debilidad siga gustando a la jerarquía católica. El caso Olavide no podrá ser nunca exhibido por la Iglesia Romana como uno más de los adocenados que, al final, ante la muerte próxima, vuelven al redil, pues siempre quedará la duda, no tanto sobre lo que había en su diálogo con Dios -que fue sincero: ese es el problema-cuanto en lo que necesitó de lo terrenal para defenderse de la tragedia de vivir el catolicismo de su época, que como siempre era puro artificio, mezcla de política y de tradición, un recurso que él hubo de emplear también en numerosas ocasiones.

Olavide creyó siempre en un Dios inmensamente bueno y protector, que daba pruebas de su existencia precisamente permitiendo al hombre la libertad de pensar y de indagar. Dios nos hizo así, libres. Algo parecido decía Mayans: "libres nos hizo Dios, libres tenemos que vivir". Pero, al final, de aquel duelo hombre-Dios (hombre hecho a su semejanza, nada menos), al que Olavide había llevado lo más arrojado de su ingenio en la plenitud de su juventud, no quedaba más que aceptar la dulzura de la Religión, la compasión del Dios que no puede castigar al redimido por su propio Hijo, la seguridad de no verse abandonado por el Padre, el tema central de El Evangelio en triunfo, en realidad, un lugar común de todos los tiempos. Como buen pantófilo, el Olavide de El Evangelio... seguía pensando lo mismo que cuando fue condenado. Pero ésa era la gran paradoja: el Dios bueno no estaba al alcance de cualquiera, menos de aquellos frailes fanáticos, de aquellos inquisidores, que no eran capaces de entenderle (ni a él, ni a Dios); tampoco de los exaltados revolucionarios. A esas alturas, no había nada que hacer, ni en el lado de la razón, ni en el del sentimiento. Quizás por eso, la solución fue abandonar la funesta manía de pensar, copiar textos franceses, beneficiarse de quienes, en los buenos tiempos, antes de la tragedia, plasmaron la dulzura del camino llano, sin riesgos, sin problematizar lo que, al fin, escapa de nuestras capacidades. Si el misterio es inescrutable, mejor abordarlo desde la placidez, desde la simplicidad, reconciliados con el fatum: el valle de lágrimas, de nuevo, y el único consuelo... pero no humano. 
Sin saberlo Olavide inauguraba una nueva época, la que se le iba a atribuir a Chateubriand, que curiosamente Ilevaba a su Atala a los grandes espacios americanos, de los que procedía el limeño, y culminaba su obra con su Genio del Cristianismo, en la antesala de la Europa de la Reacción contra la Revolución. También Olavide había contribuido con sus novelas sentimentales -muy poco conocidas a pesar de su interés ${ }^{54}$ - a prologar ese romanticismo de signo católico y reivindicador que iba a perseguir a la revolución francesa y a prolongar el duelo entre las luces y la fe.

El Evangelio... es, con todo, muy sugerente, obra largamente pensada y preparada. Como avanzó D. Ozanam, la idea de Olavide de escribir una apología del Cristianismo que demostrara que había sido injustamente condenado era vieja, nada menos que del comienzo de su exilio en 1780-81, cuando pasó por Toulouse $^{55}$. Pero la obra final no tenía esa presumible impronta de sinceridad tras los hechos trágicos; antes al contrario, además de poco original, fue muy retocada -"más que corregida, profundamente modificada" por los correctores y los censores eclesiásticos que la revisaron antes de darla a la imprenta ${ }^{56}$-, en definitiva, era ya un texto nada original a excepción de la última parte, dominada por las viejas ideas de los ilustrados españoles, ideas que pronto perdieron interés para los que sólo buscaban en el libro argumentos probatorios de la verdad del Cristianismo y de su contribución al orden social y político de la nueva época contrarrevolucionaria que se abría en Europa. Tan alejado del tema central de la obra estaba ese "programa ilustrado" final del Olavide nostálgico que los impresores franceses del XIX lo dejaron de incluir en las 13 ediciones que tuvo la obra en Francia entre 1828 y 1861, todas hechas a partir de la tercera edición de la traducción de Buynand des Echelles ${ }^{57}$.

El éxito del libro fue enorme, tanto en Francia como en España. La estrategia del anonimato con que salió la primera edición en Valencia, en 1797-98 -tan apresuradamente que se puso a la venta sólo el tomo I mientras se componía el resto de la obra-, dio buen resultado, pues añadió un argumento más a la fascinación que ejercía la vida controvertida de la víctima más selecta de la Inquisición, que ahora mostraba a todos su arrepentimiento (¿sincero?) y volvía a España. Los impresores valencianos, los hermanos Orga, se apresuraron a

54. Publicadas, con prólogo de E. NúÑEZ, en Obras narrativas desconocidas de Olavide, en www.cervantesvirtual.com.

55. OZANAM, D., "Nouveaux documents sur le séjour d'Olavide à Toulouse (novembre 1780-janvier 1781)", Melanges de la Casa de Velázquez, I (1965), pp. 279-287.

56. A las correcciones de los censores de Valencia, nombrados por la Audiencia, que no se conservan, hay que sumar las que G. Dufour vio en 1965 en el original conservado en La Carolina, "en un estante de la sección juvenil de la Biblioteca, en medio de los tebeos". Sin duda, era el original enviado a Luis de Urbina, Ileno de enmiendas, con "correcciones de otra letra que las de las dos personas que redactaron o copiaron (sin duda, bajo dictado) el texto original". DUFOUR, G., Cartas..., p. 10.

57. DUFOUR, G., Cartas..., p. 5. 
hacer una segunda tirada en 1798, mientras el impresor madrileño José Doblado la editaba en Madrid en el mismo año. Tan rápido se vendió el libro que hubo que hacer una segunda edición, a la que siguió una tercera y una cuarta al año siguiente, y otra de nuevo en 1800 (hasta hubo una edición pirata). Hubo varias más a lo largo del XIX, así como una en portugués y, más tarde, en 1827, otra en italiano.

El éxito de ventas demuestra que El Evangelio en Triunfo fue un libro muy popular, sin embargo, su superficialidad fue advertida pronto. Marcelino Menéndez Pelayo se permitió bromear con la obra, comentando que el arrepentimiento de Olavide no le había hecho escribir mejor, mientras los eruditos católicos franceses decimonónicos -que, sorprendentemente, no se dieron cuenta de que leían una traducción de autores franceses- fueron perdiendo interés por un texto que consideraron inane y repetitivo. En 1884, G. Escande escribía: "No hay duda de que no ha sido leído más que por mí durante la segunda mitad del siglo XIX. Si otra persona ha hecho otro tanto, la saludo y la compadezco" ${ }^{\prime \prime 58}$.

Así, los que han considerado a El Evangelio una obra al menos apresurada y desordenada llevan razón: no hay un plan metódico; los temas expuestos en el primer tomo se repiten en los dos siguientes; en todos se mezclan las discusiones sobre los fundamentos históricos de la fe, un tema muy manido en la llustración cristiana dieciochesca, y los argumentos sobre el valor social, moral y político de la doctrina aplicada. En suma, el libro recoge las ideas sobre el Catolicismo que habían convivido con las de los ilustrados varias décadas antes, ideas simples y muy dulzarronas que se seguirían utilizando en el siglo XIX, en un intento de la jerarquía de Ilenar el vacío intelectual en que había caído el Catolicismo, ciertamente superficial y hasta empalagoso en esa centuria y en buena parte de la siguiente hasta el Vaticano II.

Poco más da de sí este largo Evangelio, para muchos realmente plúmbeo, con que el viejo Olavide, desengañado -como cualquiera a esa edad- y arrepentido -una vez más y muchas, como todo buen católico- nos anima a penetrar en los misterios de la fe y la revelación -también, una vez más-, quizás sólo como invitación para interesarnos por su vida, esa sí, realmente fascinante.

\section{La vuelta a España}

Tras diecisiete años de exilio en Francia, volvía a España "con el cuerpo desastrado y el alma reconfortada" (Olaechea), don Pablo de Olavide y Jáuregui. A sus 73 años, tras una "vida exagerada", probadas las cárceles de la Inquisición en Madrid y las del terror revolucionario en Francia, el ilustrado cosmopolita que había dirigido el experimento político más avanzado del siglo XVIII español y que

58. Cit. En DEFOURNEAUX, M., op. Cit., p. 545. El propio Defourneaux dice que hay que "admirar a los lectores de 1797, cuyo entusiasmo ocasionó las reediciones sucesivas". 
fuera saludado por los philosophes de toda Europa como "el español que sabe pensar..." (Voltaire dixit), sólo podía ser un hombre ...desengañado.

El filósofo desengañado del que se había servido Olavide para conducir El evangelio en Triunfo era cualquiera de aquellos philosophes que formaron tras los Voltaire, Rousseau, Diderot, y que, después del regicidio y del terror revolucionario, no pudieron sino culparse de su imprevisión, jay, Candide!

El propio Olavide había sido uno de ellos, amigo de Voltaire, incensado por Diderot -que le escribió un primer esbozo biográfico-, y encumbrado por CarIos III al más alto destino: colonizar Sierra Morena, fundar pueblos, darles un instrumento racional de gobierno (dos veces aparecía la palabra felicidad en el programa de Olavide, escrito en $\left.1768^{59}\right)$, en fin, una Nueva Arcadia bajo su mando: el hombre nuevo en el mundo nuevo.

Pero ahora, treinta años después, en El Evangelio en Triunfo, Olavide Ilamaba a los filósofos sofistas, y les culpaba de todos los males. Aquellas luces, aquel filosofar despreocupadamente -entre risas y agudezas, chez Voltaire-, habían liberado todos los frenos naturales -entre ellos, los de la autoridad y la religión-, aquel optimismo y aquella fe ciega en la razón coronó una nueva diosa que ahora bendecía la anarquía y el ateísmo: lo más opuesto a "su" Razón. Eran culpables.

"El Templo en que habíamos derramado tantas lágrimas de compunción y de amor a los pies de Jesu Christo; la Iglesia en que celebrábamos todos los días los terribles Misterios, fue transformado en Templo profano que Ilamaron de La Razón (...) No era difícil conocer que la causa de todo esto era el funesto influjo de los modernos Sophistas ${ }^{\prime 60}$.

A pesar de la apariencia de sinceridad del que había cantado la palinodia, las dudas sobre la obra y sobre los verdaderos propósitos de su autor se extendieron por Madrid en cuanto se empezó a difundir El evangelio en triunfo ${ }^{61}$. Era indudable que en El Evangelio había una apología del Catolicismo intachable, pero algunos vieron rasgos demasiado impersonales y, desde luego, una falta de relación entre el texto y la verdadera causa de la que la Iglesia esperaba arrepentimiento: la condena por "hereje formal y miembro podrido de la religión" que Olavide había sufrido hacía veinte años, y a la que en El Evangelio el autor no hacía ninguna referencia. Si Olavide tenía una culpa que expiar era ésta -la personal- y no

59. LLUCH, E., Las Españas vencidas del siglo XVIII, Claroscuros de la llustración, Barcelona, Crítica, 1999, p. 153.

60. El Evangelio..., prólogo. En el proceso inquisitorial al que fue sometido Olavide una de las acusaciones fue precisamente que "solía leer libros prohibidos de Bolther, Ruso, Romano o Echiclopedia y otros que no manifestó dicho don Pablo quienes eran sus autores, debiendo decir el declarante que apenas se hallará en la librería de dicho don Pablo libro que no sea prohibido". AHN, Inq., leg. 1866-1, delación de Fray Romualdo de Friburgo.

61. La polémica llegó al Diario de Madrid nada más aparecer la primera edición madrileña. Cfr. DEFOURNEAUX, M., op. cit., p. 338. 
tanto la influencia de sus ideas y las de sus amigos en la Revolución, que a esas alturas, muchos -los ilustrados que formaban en torno al Príncipe de la Paz, por ejemplo- no estaban dispuestos a reconocer. En fin, que ni los ilustrados habían pecado tanto como para solicitar una penitencia tan extrema, ni Olavide tenía que dar cuenta de su comportamiento en la Francia revolucionaria y descristianizada, pues ya se sabía que, de nuevo, había sido una víctima, a punto de terminar en la guillotina. Su propio amigo de los buenos tiempos, y tan volteriano como él, el conde de Aranda, que había saludado la revolución en sus comienzos, llegó a ser ministro sin tener que cantar la palinodia.

Además, en El Evangelio había demasiadas apelaciones a la razón y a la filosofía -y eso que muchas fueron rectificadas en el original por el propio Olavide y por dos canónigos encargados de la corrección previa ${ }^{62}-$, lo que aumentaba las reticencias, sobre todo cuando el lector llegaba a la última parte, en la que por más que se antepusiera la Religión a todo, aparecían, aquí y allá, ideas ya conocidas del director de la colonización de Sierra Morena: la educación obligatoria de los niños -con un olor a Rousseau, innegable sobretodo cuando recomendaba retrasar la enseñanza religiosa para que fuera comprendida "racionalmente"-, la junta del bien público, la industria popular, la educación de los artesanos -que recordaban a Campomanes-, y, en fin, sus propias ideas retomadas de su Informe sobre la ley agraria, escrito en $1768^{63}$, entre las que se filtraba la denuncia de los grandes propietarios, "vampiros que chupan la sustancia pública", entre otras críticas sobre la situación social del campesinado. Ya en el prólogo, Olavide calificaba a su libro de "edificante, pero sin soltar un momento la razón de la mano; devoto, pero sin dejar jamás de ser filosófico". Hasta se permitía concitar como lectores a aquéllos de los que en otros lugares renegaba, "los que quieren hallar en todo las luces de la filosofía y de la razón" ${ }^{64}$. En definitiva, en el bando más reaccionario, y sobre todo en el brazo clerical inquisitorial, hubiera gustado más un "hereje arrepentido" que un "filósofo desengañado", como quería expresamente el inquisidor general, que no veía en el proceder de Olavide ni lo uno ni lo otro.

"Considero -decía el Inquisidor-que don Pablo de Olavide tiene hoy el concepto público de arrepentido, y aún de fortalecido en la fe de Jesucristo como manifiesta la obra anónima del Evangelio en triunfo, de que se cree su autor; pero esas voces, por más generales que sean, ni son un documento positivo, ni prestan mérito legal para destruir las resultas de su causa" ${ }^{\prime 65}$.

62. DUFOUR, G., Cartas..., pp. 10 y 26 y ss.

63. Publicado en Boletín de la Real Academia de la historia, 138-139 (1956), pp. 370-462.

64. El Evangelio..., prólogo.

65. AHN, Estado, 4.822, Expediente reservado sobre la vuelta a España de don Pablo de Olavide. Cit. en DEFOURNEAUX, M., op. cit. , p. 335 y ss. Véase también, DUFOUR, G., "EI Evangelio en triunfo devant I'Inquisiton", Hommage a Mme. Marise Jeuland, Université de Provence, 1983, pp. 225-231. 
Con un criterio estrictamente jurídico, el inquisidor recomendaba al "reo impenitente y pertinaz, que a sus anteriores yerros añadió el delito de la fuga", que volviera al convento de Murcia y demostrara allí su arrepentimiento, continuando la penitencia impuesta en su condena. Además, la sentencia inquisitorial incluía penas como la confiscación de bienes o el destierro de los sitios reales que no correspondían a su jurisdicción, sino a la del rey.

Como en el proceso de 1778, la Inquisición volvía a exhibir, veinte años después, su dependencia de la autoridad regia -le roy, le maitre de l'Inquisition, que había dicho Macanaz, otra víctima-y, por ello, el inquisidor invocaba la figura del delito civil; sólo que ahora, junto al rey, no estaba un hipócrita Roda o un confesor fanático como el padre Eleta, sino un príncipe todopoderoso, que precisamente pretendía ser el protector de víctimas como Olavide y de obras como El Evangelio en Triunfo, "que sin mí -dice Godoy en sus Memoriashabría aumentado el índice expurgatorio, porque relejeaba, decían algunos, necia o traidoramente, del sabor del veneno filosófico" ${ }^{\prime 66}$. Godoy no se engañó.

Olavide, que conocía bien la situación de la corte de Carlos IV, había elegido desde el principio la vía política, bien aconsejado por su familia, especialmente su cuñado Luis de Urbina, capitán general de Valencia y fautor de la primera edición de El Evangelio en 1797 - "se entendió conmigo para aquel buen logro", dice Godoy-, y seguramente a sabiendas de las explicaciones que se iban a ahorrar todos. Por eso, en la carta que escribió a Carlos IV mantuvo el tono de El Evangelio, insistiendo en su "desengaño". Olavide habría encontrado "en un país extranjero", "mayores amarguras que las que padeció en su patria (...), expuesto a grandes persecuciones, prisiones y riesgos de perder la cabeza en un cadalso, sin otro motivo que el de haber combatido siempre con la mayor firmeza las detestables y subversivas máximas de estos nuevos legisladores". Pero su deuda con la Inquisición quedaba reducida a fórmulas de cortesía: "no molestaré, señor, a Vuestra Majestad, con la historia de los peregrinos sucesos que por mí han pasado..."; "si he sido, Señor, objeto de escándalo en

66. GODOY, Memorias..., BAE, 88 (Madrid, 1965), p. 227. Godoy se atribuye la protección de publicaciones como El Evangelio, pues, según dice, quiso aunar luces y religión, "defender la religión con las propias armas de los enemigos"; también se atribuye la ayuda a Olavide: "yo rogué por él, cuando a mi parecer fue tiempo, yo le abrí el corazón del piadoso Carlos IV"... Seguramente, hubo de convencer al rey de que aunque "Olavide fue sin duda imprudente y afecto en demasía a las opiniones de la escuela enciclopédica (...), en su defensa y en el mismo auto protestó altamente no haber jamás negado ni descreído en su mismo interior ningún dogma de la fe católica". Godoy, que sabía que las ideas de Olavide eran las mismas que las "de sus demás amigos, conde de Aranda, conde de Campomanes, O'Reilly, Ricardos, Roda, Ricla, Almodóvar y otros sabios literatos de aquella época", atribuía su desgracia al "odio de un partido" más que a "sus propios yerros". Ibid., p. 191 y ss. Véase la excelente biografía LA PARRA, E., Manuel Godoy. La aventura del poder. Barcelona, 2002. Sobre el nuevo clima político en torno a Carlos IV y Godoy y la supeditación de la Inquisición al poder civil, en EGIDO T., Los Borbones. Carlos IV, Madrid, Arlanza, 2001, pp. 249 y ss.; también, DUFOUR, G., op. cit., p. 16 y ss.; y DEFOURNEAUX, M., op. cit., p. 334 y ss. 
España, he procurado repararlo..."; en fin, Olavide manifestaba expresamente que no iba a entrar en "reclamaciones ni exámenes que contradigan o desmientan el concepto público sobre los procedimientos que he sufrido". En suma, sólo aspiraba a "la restauración de mi honor y el de toda mi familia" y a "hacer una muerte cristiana"67.

Con El Evangelio en Triunfo por delante, pero sobretodo con la protección regia -y de Godoy-, Olavide tenía todas las posibilidades de salir airoso de la prueba. Para unos sería un mal desengañado, para otros, un falso arrepentido; la mayoría, sin embargo, creería en su sinceridad, y en lo que tanto gusta en el seno del catolicismo: el efecto de la cercanía de la muerte, la hora de la verdad en la que Dios no abandona a nadie. El riguroso Menéndez Pelayo calificó El Evangelio en triunfo de "intachable, sin vislumbres ni aun remotos de doblez e hipocresía", y creyó en el arrepentimiento sincero de Olavide. En todo caso, la oveja "atolondrada, pero nunca descarriada" ${ }^{68}$, volvía al redil y dejaba de sufrir, que era lo importante.

Al margen de la sinceridad del católico Olavide, que no debe -ni debió- ser cuestionada, El Evangelio en triunfo puede ser el producto de un desengaño más o menos expresado literariamente, pero no es ni con mucho una declaración de fe religiosa, sentida y doliente, como las que había hecho el propio Olavide ante el inquisidor Beltrán o ante el ministro Roda veinte años antes. Pero ésta es la paradoja del que busca sinceramente en la Religión un camino personal distinto del que las jerarquías imponen a quienes prefieren el premio de obedecer al castigo de pensar. Una paradoja, en fin, que a Olavide le obligó a confesar una y otra vez lo que a todo el mundo se le daba por supuesto en la España del XVIII: que era ...católico.

En 1798, Pablo de Olavide se había ganado la tranquila repatriación, el retiro final y morir tranquilamente. Pasó por Madrid donde desechó ofrecimientos y se retiró a Baeza, donde murió el 25 de febrero de 1803.

67. La carta, en DEFOUNEAUX, M., op. cit.p. 334.

68. OLAECHEA, R., Viajeros españoles del XVIII en el Alto Pirineo francés. Logroño, 1985. 